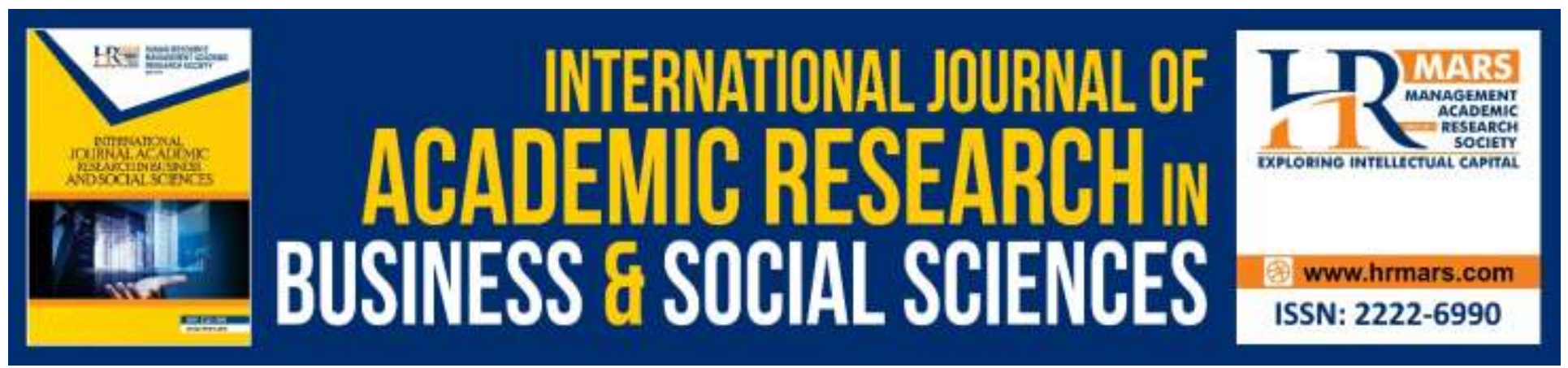

\title{
Validating a Partial of Amabile's Componential Theory: A Psychometric Procedure
}

Hamimah Hashim, Rosilawati Sueb, Siti Maftuhah Damio, Nadiyah Hashim

To Link this Article: http://dx.doi.org/10.6007/IJARBSS/v9-i13/6236

DOI: $10.6007 /$ IJARBSS/v9-i13/6236

Received: 27 March 2019, Revised: 19 June 2019, Accepted: 22 July 2019

Published Online: 28 August 2019

In-Text Citation: (Hashim, Sueb, Damio, \& Hashim, 2019)

To Cite this Article: Hashim, H., Sueb, R., Damio, S. M., \& Hashim, N. (2019). Validating a Partial of Amabile's Componential Theory: A Psychometric Procedure. International Journal of Academic Research in Business and Social Sciences, 9(13), 1-13.

Copyright: (C) 2019 The Author(s)

Published by Human Resource Management Academic Research Society (www.hrmars.com)

This article is published under the Creative Commons Attribution (CC BY 4.0) license. Anyone may reproduce, distribute, translate and create derivative works of this article (for both commercial and non-commercial purposes), subject to full attribution to the original publication and authors. The full terms of this license may be seen

at: http://creativecommons.org/licences/by/4.0/legalcode

Special Issue: Revolutionizing Education: Challenges, Innovation, Collaboration, 2019, Pg. 1 - 13

http://hrmars.com/index.php/pages/detail/IJARBSS

JOURNAL HOMEPAGE

Full Terms \& Conditions of access and use can be found at http://hrmars.com/index.php/pages/detail/publication-ethics 


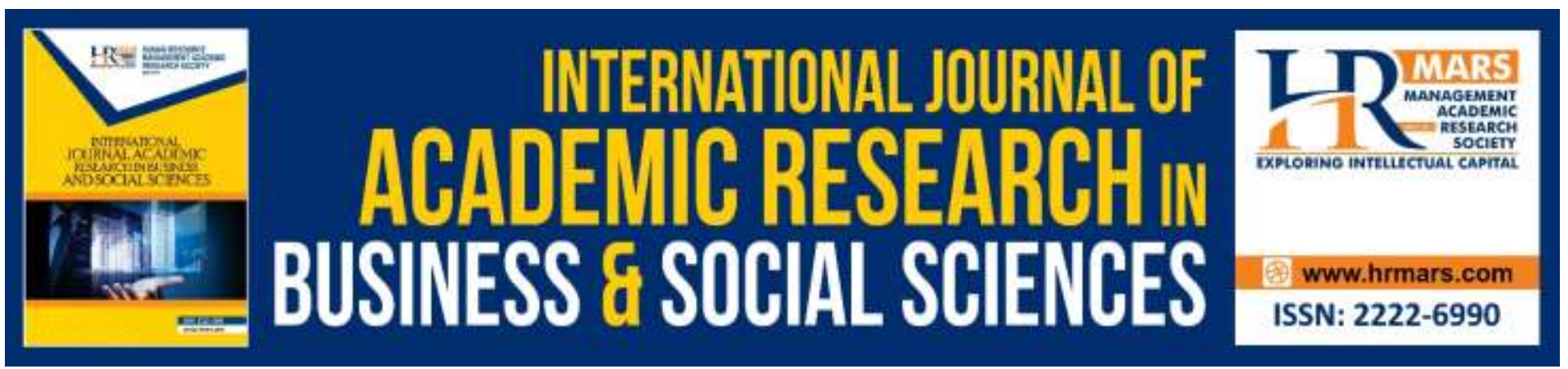

\title{
Validating a Partial of Amabile's Componential Theory: A Psychometric Procedure.
}

\author{
Hamimah Hashim, Rosilawati Sueb, Siti Maftuhah Damio
} Faculty of Education, UiTM Puncak Alam Campus, 42300 Puncak Alam, Selangor, Malaysia

\author{
Nadiyah Hashim \\ ACIS, UiTM Perlis, 02600, Arau, Perlis, Malaysia
}

\begin{abstract}
Investigation of the learning environment in higher learning institutions is essential in assisting educational institutions to improve students' learning. This study examines a partial hypothesized model whch postulates the relationships between learning environment factors; namely lecturers, peers, and physical learning environment and motivational orientation (controlled). The hypothesized model in this study is adapted from Amabile's Conceptualization of Motivational Energy (1996). The objectives of this study are to examine the structural relationships among the variables as well as to validate the instruments and model. Data is gathered using responses to items survey $(n=374)$ among first degree graduating students in UiTM Shah Alam. The analysis of the data involves structural relationships and models which have been tested for their fitness via AMOS version 16.0. The percentage of variance explained by motivational orientation variable is $72 \%$ (controlled orientation). The findings indicate that there are significant relationships between the variables measured at $p<0.05$. The relationships among the variables are not only based on previous empirical findings but also built upon a strong theoretical framework (Amabile's Componential Theory, 1996). Moreover, this study establishes the psychometric properties of the instruments and validates the hypothesized models. The findings support the assumptions of Amabile's partial Componential Theory. Finally, theoretical and practical implications are discussed in the context of learning environments to verify that these factors are significant indicators for their motivational orientation.
\end{abstract} Keywords: Componential Theory, Psychometric, Validating

\section{Introduction}

Malaysia practices democratization of education that encourages its people to embark on tertiary learning which consequently influenced the surge in the establishment of higher learning institutions and universities since 2017 with a total of 20 public universities that made up 532,049 students 
nationwide (Quick Facts, 2017). Universities are the entities which are expected to produce quality, knowleadgable, marketable and highly motivated workforce that are competitive in the employability market and to boost national progress. Importantly, the university can be the preparational place for graduates to enhance their motivation level. However, the increasing number of unemployed graduates, due to lack of competency in certain skills, is a concerning matter that should be appropriately addressed at the managerial level. There are three contributing factors which have been identified in the rise of unemployment among graduates namely; graduates' attributes, lecturers' competency and quality of education (Zaliza \& Safarin, 2014). Hence, it is crucial for the stake holders in higher educational institutions to equip their graduates to meet the demands of the changing competitive workforce.

The above discussion brings to light certain issues that requires further attention. Anggia and Nurul (2014) had identified that the environment affect individual motivation within working and non-working environment which subsequently suggested that any studies involving motivation should include the environment as an affecting factor. Therefore, this present study examines the elements of learning environment that affect university students' motivation level. It is essential for the researchers to gauge the influence of the learning environment in UiTM on graduating students' motivational scale. The hypothesized model in this study was adapted from Amabile's Conceptualization of Motivational Energy (1996) with an examination of the structural relationships among the variables involved using Structural Equation Model (SEM). The relationships among the variables (Figure 1) were built based on a sound and influential theoretical framework, which refers to Amabile's Componential Theory (1996) as well as previous empirical findings. Thus, the objectives of this study are; i) to validate the Partial Model, and ii) to examine the psychometric properties of the measurement models based on a Partial of Amabile's Componential theory.

\section{Theoretical Framework}

The theoretical framework for this study is drawn from the conceptualization of motivational energy by Amabile (1996). This study aims to validate a part of Amabile's theory, by only focusing on the social environment and motivation aspects. Amabile had asserted that the human behaviour results from a combination of individual qualities, thinking skills, and social settings. Therefore, this study applies Amabile's theory to study UiTM learning environment. This theory suggests that extrinsic motivation is divided into 'synergetic extrinsic motivation' and 'non-synergetic extrinsic motivation'. A positive social environment can influence synergetic extrinsic motivation. Based on the Figure 1, the social environment factors connoting control will lead to non-synergetic extrinsic motivation and will detract from intrinsic motivation. 
INTERNATIONAL JOURNAL OF ACADEMIC RESEARCH IN BUSINESS AND SOCIAL SCIENCES

Vol. 9, No. 13, Special Issue: Revolutionizing Education: Challenges, Innovation, Collaboration., 2019, E-ISSN: 2222-6990 @ 2019 HRMARS

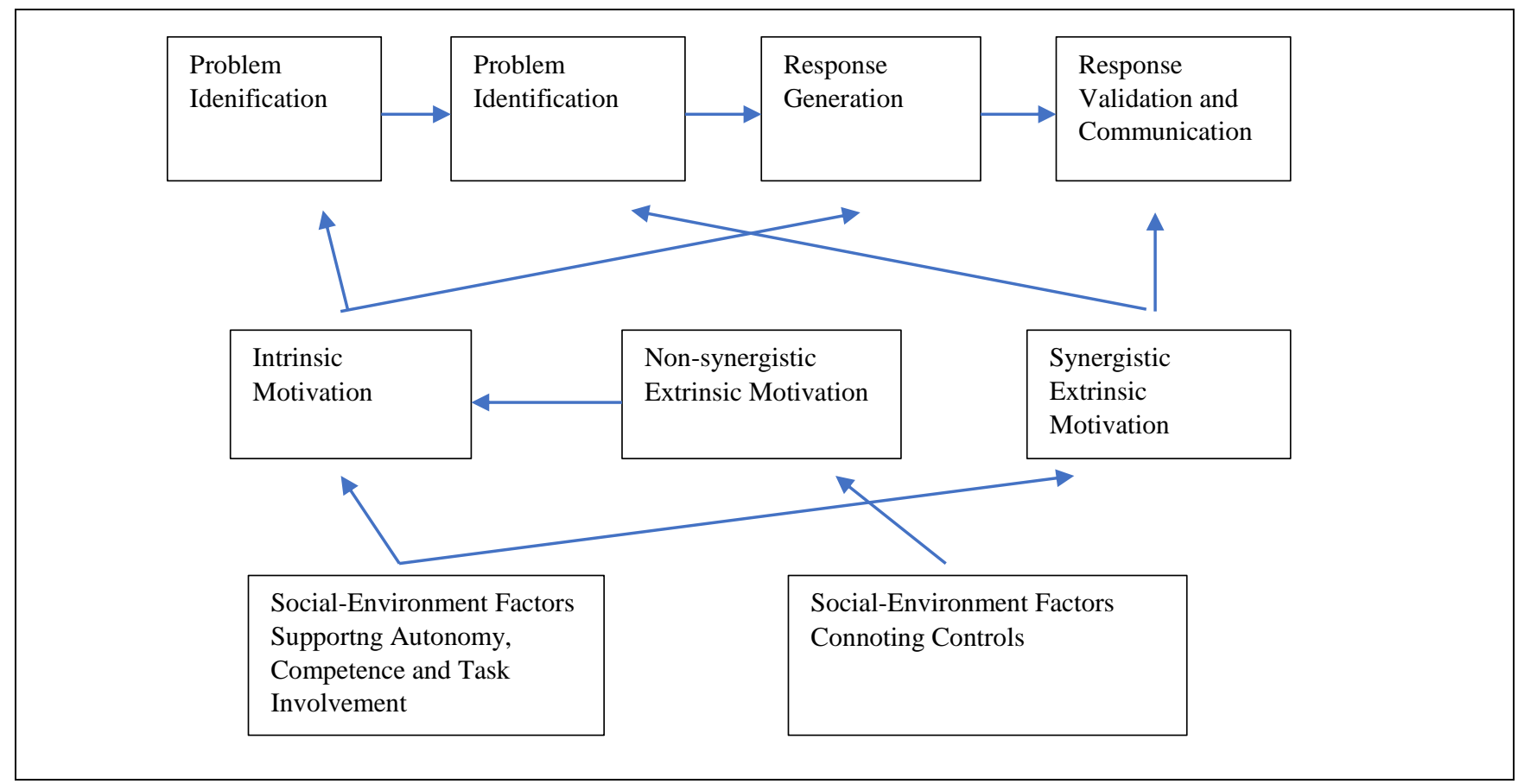

Figure 1. Details of the Componential Model: Mechanism of SocialEnvironmentInfluence on Creativity

Since focus of the study is on UiTM graduating students, the social environment in this context refers to the learning environment in UiTM which include sub-constructs like lecturers, peer, and physical learning environment. In this study, the learning environment serves as an exogenous variable and motivational orientations as the dependent variable.

Amabile's Componential Model suggests that social environment influences task motivation. Therefore, the researchers decided to employ Deci and Ryan Motivational Orientation scales (1985) because Amabile's (1996) conceptualizations of synergetic and non-synergetic extrinsic motivation were derived from Deci and Ryan's idea concerning 'informational' versus 'controlling' extrinsic motivators. The measures of graduating students' motivation are deemed appropriate as this theory (Causality Orientation Theory) is related to the causes of individual's choices.

Human behaviour is often influenced by their motivation levels. One of the prominent theories of human motivation was founded by Deci and Ryan (1985) and the theory is known as Selfdetermination theory (SDT). According to Deci and Ryan, SDT is based on empirical evidence of human motivation and this theory highlights the social conditions that boost or diminish human motivation. SDT is applicable to workplace relationships, parenting styles, and educational settings.

\section{Research Methodology}

This study employs the quantitative research approach and the cross-sectional survey design. The use of this method is suitable to test and validate the proposed research objectives because the researchers analysed the model via Structural Equation Modeling (SEM) which required a relatively extensive sample pool. 


\section{Population and Sampling}

The population of this study is UiTM graduating students in Shah Alam Campus $(\mathrm{N}=15,422)$. UiTM has 3 main clusters of studies, namely Social Science and Humanities, Science and Technology; and Management and Business. Table 1 depicts the percentage and the total number of sample in the study based on proportional stratified sampling.

Table 1. Percentage and Total Number of Sample

\begin{tabular}{lllll}
\hline & $\begin{array}{l}\text { SOCIAL SCIENCE } \\
\text { AND } \\
\text { HUMANITIES }\end{array}$ & $\begin{array}{l}\text { SCIENCE } \\
\text { TECHNOLOGY }\end{array}$ & $\begin{array}{l}\text { ANDANAGEMENT } \\
\text { AND BUSINESS }\end{array}$ & $\begin{array}{l}\text { Total } \\
\text { population }\end{array}$ \\
\hline $\begin{array}{l}\text { Total no of } \\
\text { students }\end{array}$ & 2598 & 9055 & 3769 & 15,422 \\
$\begin{array}{l}\text { Percentage } \\
\begin{array}{l}\text { No of } \\
\text { students }\end{array}\end{array}$ & $17 \%$ & $59 \%$ & $24 \%$ & 100 \\
involved & 65 & 224 & 91 & 380 \\
\hline
\end{tabular}

In this study, the first step of the sampling technique involved a proportional stratified sampling in which the percentage of the respondents is determined. The second step of sampling is cluster sampling. Ary, Jacobs, Razavieh, and Sorensen (2006) noted that cluster sampling is a kind of probability sampling and it is referred as cluster sampling because the unit chosen is not an individual but a group of individuals who are naturally collective.

\section{Findings: Psychometric Properties of the Hypothesized Measurement Models}

The following discussion is the findings for the psychometric properties of the hypothesized measurement model, responding to the first and second research questions. When the researchers were analyzing the data using the Structural Equation Model (SEM), it was recommended to follow a two-step procedure. The first step is the analysis of the measurement model via confirmatory factor analysis (CFA) and then followed by the second step; the analysis of the structural model. For the CFA and SEM, a covariance matrix was analyzed and a maximum likelihood estimation procedure was used.

\section{Measurement Model for Peer Construct}

The model was compared using chi-square ( $\chi 2), \chi 2 / d f, C F I, T L I$, and RMSEA. Table 2 reveals the measurement model for the peer construct. 
INTERNATIONAL JOURNAL OF ACADEMIC RESEARCH IN BUSINESS AND SOCIAL SCIENCES

Vol. 9, No. 13, Special Issue: Revolutionizing Education: Challenges, Innovation, Collaboration., 2019, E-ISSN: 2222-6990 @ 2019 HRMARS

Table 2 Goodness-Of-Fit Indexes of the CFA Measurement Model for Peer Construct

\begin{tabular}{lll}
\hline Fit statistic & Value & Description \\
\hline$\chi^{2}$ & 0.709 & model vs. saturated \\
$\chi^{2} / \mathrm{df}$ & 0.709 & baseline vs. saturated \\
$\mathrm{RMSEA}$ & 0.00 & Root mean squared error of approximation \\
$\mathrm{CFI}$ & 0.99 & Comparative fit index \\
$\mathrm{TLI}$ & 0.99 & Tucker-Lewis index \\
\hline
\end{tabular}

Note. $\chi 2$ : Chi-square goodness of fit; df: Degrees of Freedom; CFI: Comparative Fit Index; TLI: TuckerLewis fit index (TLI); RMSEA: Root Mean Square Error.

Table 2 shows the overall measurement model with all parameters estimates which were obtained from the test carried out via CFA. Results of the SEM analysis show the measurement of $\chi^{2}$ $=0.709, \chi^{2} / \mathrm{df}=0.709, \mathrm{RMSEA}=0.00, \mathrm{TLI}=0.99$ and $\mathrm{CFI}=0.99$. All kinds of evaluations result in a goodfitting model with the accepted fitness information. Figure 2 is the finalized measurement model for peer construct.

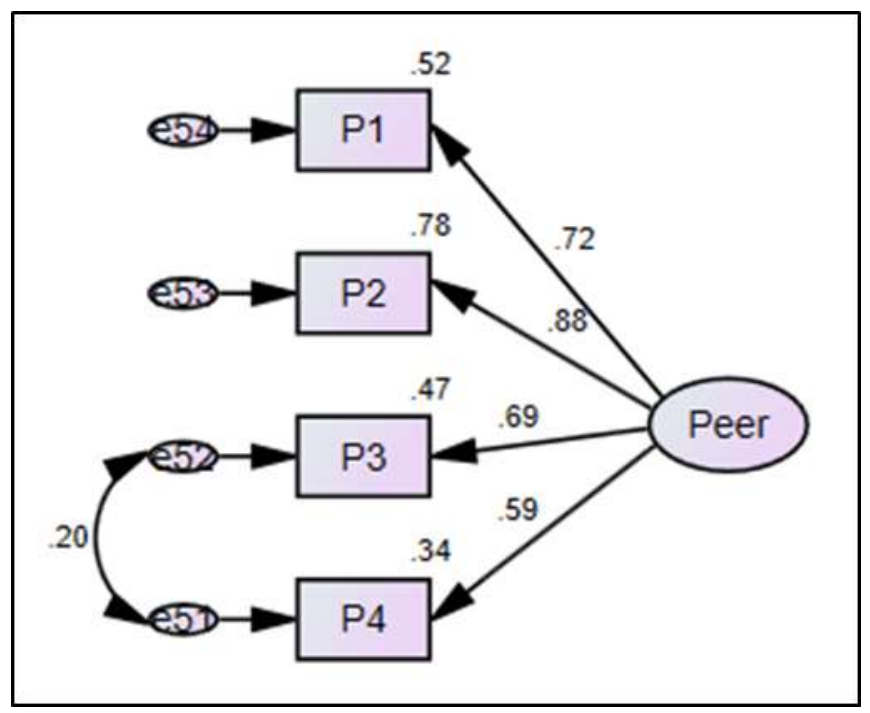

Figure 2. The Finalized Measurement Model for Peer Construct

Figure 2 illustrates the finalized measurement model for peer construct between observed variables and latent variables. Moreover, we assessed strength associated with the error covariance term relating items P4 and P3. Fit indices of the finalized measurement model for peer construct with error covariance offered a significantly better fit to the data.

\section{Measurement Model for Lecturer Construct}

The models were compared to using chi-square ( $\chi 2), \chi 2 / d f, C F I, T L I$, and RMSEA. Table 3 shows the measurement model for lecturer construct. 
INTERNATIONAL JOURNAL OF ACADEMIC RESEARCH IN BUSINESS AND SOCIAL SCIENCES

Vol. 9, No. 13, Special Issue: Revolutionizing Education: Challenges, Innovation, Collaboration., 2019, E-ISSN: 2222-6990 @ 2019 HRMARS

Table 3 Goodness-of-Fit Indexes of the CFA Measurement Model for Lecturer Construct

\begin{tabular}{lll}
\hline Fit statistic & Value & Description \\
\hline$\chi^{2}$ & 61.603 & model vs. saturated \\
$\chi^{2} /$ df & 2.567 & baseline vs. saturated \\
RMSEA & 0.065 & Root mean squared error of approximation \\
CFI & 0.973 & Comparative fit index \\
TLI & 0.956 & Tucker-Lewis index \\
\hline
\end{tabular}

Note. X2: Chi-square goodness of fit; df: Degrees of Freedom; CFI: Comparative Fit Index; TLI: TuckerLewis fit index (TLI); RMSEA: Root Mean Square Error.

Table 3 displays the overall measurement model with all parameters estimates resulted from the test carried out via CFA. Results of the SEM analysis show the measurement of $\chi 2=61.603, \chi 2 / \mathrm{df}$ $=2.567, \mathrm{RMSEA}=0.065, \mathrm{TLI}=0.956$ and $\mathrm{CFI}=0.973$. All kinds of evaluations result in a good-fitting model with the accepted fitness information. Figure 4.4 became the finalized measurement model for lecturer construct.

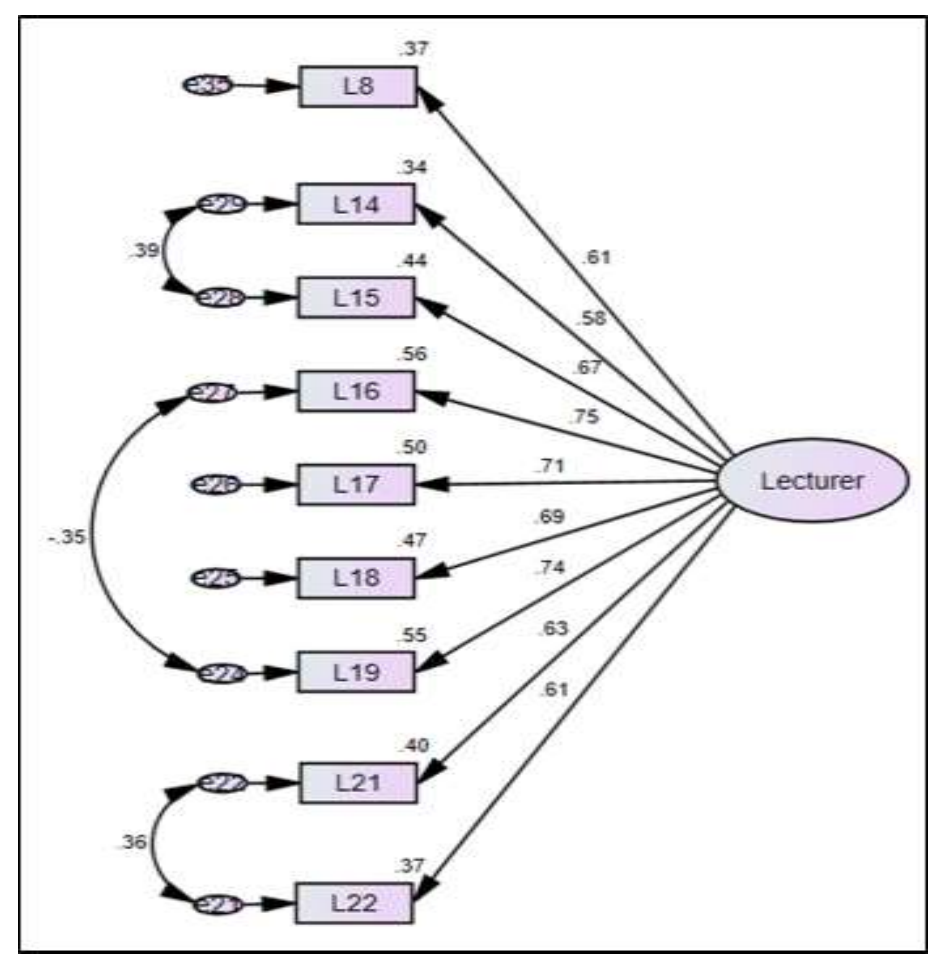

Figure 3. The Finalized Measurement Model for Lecturer Construct

Figure 3 illustrates the finalized measurement model for lecturer constructs between observed variables and latent variables. Moreover, we assessed strength associated with the error covariance term relating item LT14 and LT15, LT16 and LT19, LT21 and LT22. Fit indices for the finalized measurement model for lecturer construct with error covariance offered a significantly better fit to the data. 
INTERNATIONAL JOURNAL OF ACADEMIC RESEARCH IN BUSINESS AND SOCIAL SCIENCES

Vol. 9, No. 13, Special Issue: Revolutionizing Education: Challenges, Innovation, Collaboration., 2019, E-ISSN: 2222-6990 @ 2019 HRMARS

\section{Measurement Model for Physical Learning Environment Construct}

The models were compared to using chi-square $\left(\chi^{2}\right), \chi^{2} / d f, C F I, T L I$, and RMSEA. Table 4 shows the measurement model for physical learning environment construct.

Table 4. Goodness-of-fit indexes of the CFA Measurement Model for Physical Learning Environment Construct

\begin{tabular}{lll}
\hline Fit statistic & Value & Description \\
\hline$\chi^{2}$ & 19.489 & model vs. saturated \\
$\chi^{2} / \mathrm{df}$ & 2.165 & baseline vs. saturated \\
RMSEA & 0.056 & Root mean squared error of approximation \\
$\mathrm{CFI}$ & 0.988 & Comparative fit index \\
$\mathrm{TLI}$ & 0.980 & Tucker-Lewis index \\
\hline
\end{tabular}

Note. X2: Chi-square goodness of fit; df: Degrees of Freedom; CFI: Comparative Fit Index; TLI: TuckerLewis fit index (TLI); RMSEA: Root Mean Square Error.

Table 4 shows the overall measurement model with all parameter estimates resulted from the test carried out via CFA. Results of the SEM analysis show the measurement of $\chi^{2}=19.489, \chi^{2} / \mathrm{df}$ $=2.165, \mathrm{RMSEA}=0.056, \mathrm{TLI}=0.980$ and $\mathrm{CFI}=0.988$. All kinds of evaluations result in a good-fitting model with the accepted fitness information. Figure 4 is the finalized measurement model for physical learning environment construct.

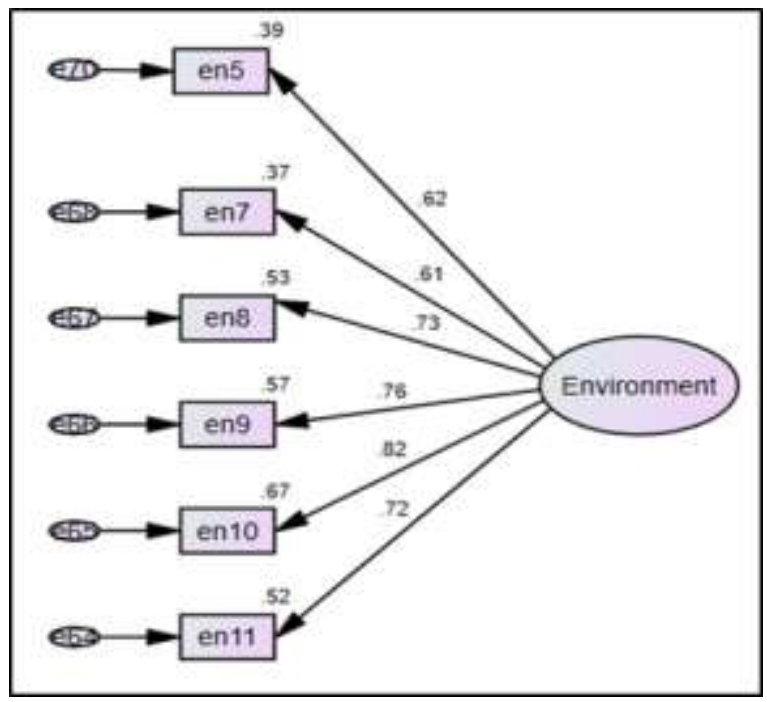

Figure 4. The Finalized Measurement Model for Physical Learning Environment Construct

Figure 4 displays the finalized measurement model for physical learning environment constructs between observed variables and latent variables. All kinds of evaluations result in an acceptable model fit for physical learning environment construct. 
INTERNATIONAL JOURNAL OF ACADEMIC RESEARCH IN BUSINESS AND SOCIAL SCIENCES

Vol. 9, No. 13, Special Issue: Revolutionizing Education: Challenges, Innovation, Collaboration., 2019, E-ISSN: 2222-6990 @ 2019 HRMARS

\section{Measurement Model for Controlled Orientation Construct}

The models were compared to using chi-square $\left(\chi^{2}\right), \chi^{2} / d f, C F I, T L I$, and RMSEA. Table 5 shows the measurement model for control orientation construct.

Table 5. Goodness-of-Fit Indexes of the CFA Measurement Model for Controlled Orientation Construct

\begin{tabular}{lll}
\hline Fit statistic & Value & Description \\
\hline$\chi^{2}$ & 4.544 & model vs. saturated \\
$\chi^{2} / \mathrm{df}$ & 2.272 & baseline vs. saturated \\
RMSEA & 0.058 & Root mean squared error of approximation \\
CFI & 0.993 & Comparative fit index \\
TLI & 0.979 & Tucker-Lewis index \\
\hline
\end{tabular}

Note. $\chi 2$ : Chi-square goodness of fit; df: Degrees of Freedom; CFI: Comparative Fit Index; TLI: TuckerLewis fit index (TLI); RMSEA: Root Mean Square Error.

Table 5 indicates the overall measurement model with all parameter estimates resulted from the test carried out via CFA. Results of the SEM analysis show the measurement of $\chi 2=4.544, \chi 2 / \mathrm{df}$ $=2.272, \mathrm{RMSEA}=0.058, \mathrm{TLI}=0.979$ and $\mathrm{CFI}=0.993$. All kinds of evaluations result in a good-fitting model with the accepted fitness information. Figure 5 is the finalized measurement model for control orientation construct.

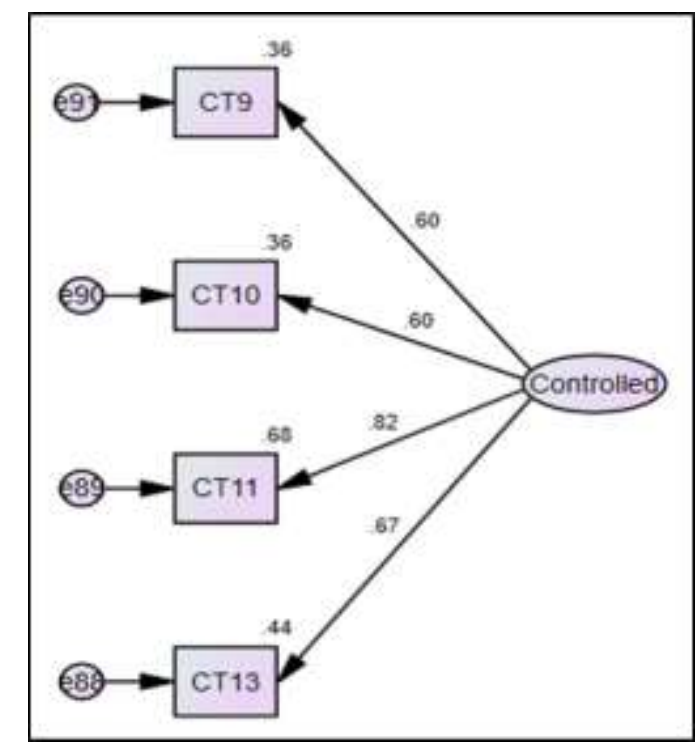

Figure 5. The Finalized Measurement Model for Controlled Orientation Construct

Figure 5 reveals the finalized measurement model for control orientation construct between observed variables and latent variables. All kinds of evaluations result in an acceptable model fit for controlled orientation construct.

This study examines the degree of convergent validity which refers to the extent to which indicators or items of a specific construct converge or share a high proportion of variance in common. 
INTERNATIONAL JOURNAL OF ACADEMIC RESEARCH IN BUSINESS AND SOCIAL SCIENCES

Vol. 9, No. 13, Special Issue: Revolutionizing Education: Challenges, Innovation, Collaboration., 2019, E-ISSN: 2222-6990 @ 2019 HRMARS

To evaluate the degree of convergent validity, the researchers need to check for construct loadings, variance extracted (AVE) and constructs reliability.

Table 6 Parameter Estimates for the CFA Measurement Models of the 4 Constructs

\begin{tabular}{|c|c|c|c|c|}
\hline Constructs & Indicators & $\begin{array}{l}\text { Factor } \\
\text { loading }\end{array}$ & $\begin{array}{l}\text { Composite } \\
\text { reliability }\end{array}$ & $\begin{array}{l}\text { AVE } \\
\text { (Variance extracted) }\end{array}$ \\
\hline Learning & en5 & .62 & .86 & .51 \\
\hline \multirow[t]{5}{*}{ Environment } & en7 & .61 & & \\
\hline & en8 & .73 & & \\
\hline & en9 & .76 & & \\
\hline & en10 & .82 & & \\
\hline & en11 & .72 & & \\
\hline \multirow[t]{9}{*}{ Lecturer } & L8 & .61 & .88 & .50 \\
\hline & L14 & .58 & & \\
\hline & L15 & .67 & & \\
\hline & L16 & .75 & & \\
\hline & L17 & .71 & & \\
\hline & L18 & .69 & & \\
\hline & L19 & .74 & & \\
\hline & L21 & .63 & & \\
\hline & L22 & 61 & & \\
\hline \multirow[t]{4}{*}{ Peer } & P1 & .72 & .81 & .53 \\
\hline & $\mathrm{P} 2$ & .88 & & \\
\hline & P3 & .69 & & \\
\hline & P4 & .59 & & \\
\hline \multirow[t]{4}{*}{ Controlled } & СТ9 & .60 & .77 & .50 \\
\hline & CT10 & .60 & & \\
\hline & CT11 & .82 & & \\
\hline & CT13 & .67 & & \\
\hline
\end{tabular}

Results from the structural equation-based approach of CFA show a parameter estimates for the 4 constructs (see Table 6). Convergent validity checks indicated that all loadings are significant as there are higher than 0.50 . The values for construct reliability for all constructs are above 0.70 revealing the adequacy for convergence or internal consistency.

\section{Convergent Validity}

For construct validity inspection, the researchers run a convergent validity test that examines the degree which measures the constructs that should be theoretically related. As for the physical learning environment, it is measured by 6 items. The factor loadings ranged from $\beta=.87, t=11.26$ to $\beta=1.28, t=14.84$ and are significant at $p<.05$; hence, convergent validity was established for this construct. In addition, support from the lecturers is measured by 9 items. The factor loadings ranged 
from a low of $\beta=.96, t=11.45$ to a high of $\beta=1.19, t=13.01$ and are significant at $p<.05$; hence, convergent validity was confirmed for this construct.

Another exogenous variable is supported from peers and it is measured by 4 items. The factor loadings ranged from $\beta=.84, t=10.47$ to $\beta=1.18, t=13.63$ and were significant at $p<0.05$; hence, convergent validity is also established for this construct.

As for Controlled motivation, it was measured by 4 items. The factor loadings ranged from $\beta=.82, t=8.84$ to $\beta=1.82, t=10.10$ and are significant at $p<0.05$; hence, convergent validity is established for this construct.

\section{Discriminant Validity}

Discriminant validity is the extent to which a construct actually diverges from other constructs. All construct variance extracted (AVE) values should be higher than the corresponding squared inter-construct correlation estimates (SIC). Table 7 shows the values of AVE and SIC of the constructs involved.

Table 7. Discriminant Validity Checks by Comparing the Average Variance Extracted and the Square of Correlation

\begin{tabular}{lllll}
\hline $\begin{array}{l}\text { Average Variance } \\
\text { Extracted (AVE) }\end{array}$ & .50 & .53 & .51 & .50 \\
$\begin{array}{l}\text { Inter-construct } \\
\text { Correlations Squared }\end{array}$ & Lecturer & Peer & Envi & Controlled \\
\hline $\begin{array}{l}\text { Lecturer } \\
\text { Peer }\end{array}$ & 1 & & & \\
Envi & .37 & 1 & & \\
Controlled & .50 & .32 & 1 & \\
& -.01 & .14 & .03 & 1 \\
\hline
\end{tabular}

All variance extracted (AVE) values in Table 7 are larger than the corresponding squared interconstructs correlation estimates (SIC). This implies that the indicators have more in common with the construct they are related with than they do with other constructs. Based on this finding, the measurement model of the study establishes discriminant validity.

\section{Discussion of Findings}

It was identified that all measurement models which are hypothesized, adequately fit with the data collected within the UiTM context. This model incorporates a combination of the measurements for all constructs involved in this study. The measurement models tested earlier were then interpolated in the structural model and the fit indices were evaluated using the Analyses of Moment Structures (AMOS) version 16.0 program. In order to validate the fitness of the overall measurement model with data, the goodness-of-fit indexes used were the comparative fit index: CFI, root mean square error of approximation: RMSEA and Normed Chi-Square: cmin/df.

Another essential task is to establish the convergent and discriminant validity of the instruments used in the study. For this purpose, the disattenuated correlations amongst the 
constructs were also examined. It should be reiterated here that the test of absolute model fit. In this study, the researchers did not depend on the value of the chi-square statistics as the only measures for identifying model fitness. The Chi-square normally tests the difference between the sample covariance matrix and the restricted covariance matrix, with the assumption that the residual discrepancy between them is zero. Thus, when the $p$-value is more than .05 , it indicates a good fitting model.

As mentioned earlier, the value of Chi-square is strict and rigorous and it may direct to the rejection of the null hypothesis because of its sensitivity to large sample sizes. Additionally, Miles and Shevlin (2007) disclosed that the Chi-square index is also influenced by the reliability of the factors studied, those of high associations among the observed factors and of lower unique variance held by each factor direct to model rejection. This is due to the fact that high-reliability value gives greater power to the tested model and causes a rise in Chi-square index. As a result, it was suggested that incremental fit indices, which is the Comparative Fit Index (CFI), are also observed in addition to absolute Chi-square values (Miles \& Shevlin, 2007). Additionally, the Root Mean Square Residual (RMSEA) was also taken into consideration through observation of its magnitude. Thus, the presence of Chi-square statistics in the study is primarily for informative purposes.

The first index, Comparative Fit Index (CFI) compares the hypothesized model with the independence model, which is a highly strict model. In general, the values of CFI and Normed Fit Index (NFI) are reliable; thus, only the values of CFI is conveyed in this study. Another efficient index used for testing model fitting is the Root Square Error Approximation (RMSEA). RMSEA analyzes the inconsistency between the population covariance matrix and restricted model covariance matrix and estimates the potential error (Bryne, 2010). Furthermore, the lower bound and upper bound values were also reported since the analysis of the confidence interval shows that we can be $90 \%$ confident that the RMSEA value in the population will fall within the bounds, representing a good degree of precision (Bryne, 2010).

The findings revealed that the overall measurement model represented a good-fitting model with the fitness evidence (see Table 2, 3, 4 and 5). All $\beta$ - weight was significant at $p<.05$, with loading values ranging from .50 to .97 . Results also indicated that the discriminant validity was also recognized when none of the dissattenuated correlations amongst the constructs was more than .90 (John \& Benet- Martinez, 2000).

Results from the structural equation-based approach of CFA show a parameter estimates for the 4 constructs (see Table 6). Convergent validity checks indicated that all loadings are significant as there are above .50. The values for construct reliability for all constructs are above .70 which suggests sufficient convergence or internal consistency. The discriminant validity refers to the extent to which a construct is actually different from other constructs. Indeed, all construct variance extracted (AVE) values should be bigger than the corresponding squared inter-construct correlation estimates (SIC). Table 7 shows the values of AVE and SIC of the constructs involved.

\section{Conclusion}

The study lends support for Amabile's Componential theory which assumes that the environment plays a pivotal role in influencing individuals' motivational orientation. This theory stresses the significance of social contexts, which hold the idea that individual motivation is affected by both dispositional and situational variables. The current study validates a part of Amabile's theory 
which examines the learning environmental factors such as support from lecturers, peers and physical learning environment on graduates' motivation. Following Amabile's theoretical notion, the social settings factors are more vigorous in the way they influence an individual's motivation. The hypothesized models were found to be adequately fit with the data, the verification procedure of these instruments has gone through confirmatory factor analysis (CFA) via AMOS. Based on the findings, all the instruments were verified as reliable and valid to be consumed in the setting of the current research. Despite the evidence of good psychometric properties of the instruments used in this study, the validity of the instruments in a similar setting needs to be further enhanced through replication of the study.

\section{References}

Amabile, T. M. (1996). Creativity in Context: Update to the Social Psychology of Creativity. Westview Press, Inc.

Anggia, P., \& Nurul, I. (2014). Impact of the Environment Support on Creativity: Assessing the mediating role of intrinsic motivation. Procedia-Social and Behavioral Sciences. Volume 115, 21 Feb 2014, 102-114.

Ary, D., Jacobs, L. C., \& Razaveih, A. (2006). Introduction to research in education (6th ed.). Belmont, CA: Wadsworth/Thompson Learning.

Byrne, B. (2010). Factor analytic models: Viewing structure of an assessment instrument from three different perspectives. Journal of Personality Assessment, 85, 17-32

Chavan, R. R., \& Surve, A. Y., (2014). Assesing parameters of employability skills: an employers' perspective. Asian Journal of Management Research. 5 (2). 254-260

Deci, E. L., \& Ryan, R. M. (1985). The general causality orientations scale: Self-determination in personality. Journal of Research in Personality, 19, 109-134.

John, O. P, \& Benet-Martinez, V. (2000). Measurement: Reliability, construct validation and scale construction. In H.T. Reis \& C.M. Judd (eds.) Handbook of research methods in social and psychological personality, 339-369.

Miles, J. \& Shevlin, M. (2007). A time and a place for incremental fit indices. Personality and Individual Differences, 42, 869-874.

Quick Facts : Malaysia Educational Statistics. Educational (2017). Data Sector. Educational Planning and Research Division. Ministry of Education Malaysia

Zaliza, H., Nordin, S. N. (2014). Unemployment among Malaysia Graduates: Graduates'Attributes, Lecturers' Competency and Quality of Education. Procedia- Social and Behavioral Sciences. 112 , 1056-1063. https://doi.org/10.1016/j.sbspro.2014.01.1269 